\title{
Allergic contact dermatitis to shoes: contribution of a specific series to the diagnosis*
}

\author{
Rosana Lazzarini ${ }^{1}$, Rodolfo Ferreira Mendonça ${ }^{1}$, Mariana de Figueiredo Silva Hafner ${ }^{1}$
}

DOI: http:/ / dx.doi.org/10.1590/abd1806-4841.20187370

\begin{abstract}
BACKGROUND: In our country, the Brazilian Standard Series is the most used for the etiological diagnosis of allergic contact dermatitis to shoes. However, there is no assessment of the usefulness of specific allergens for shoes.

OвJестіVEs: To measure the improvement in diagnostic accuracy of allergic contact dermatitis to shoes with the use of a specific complementary series in patch testing and describe the characteristics of the affected population, such as gender, location of lesions, time of evolution, and the most common allergens.

MetHODS: This retrospective study evaluated the results of 52 patients with suspected shoe dermatitis subjected to patch tests with the standard and specific series to quantify the gain in diagnostic accuracy.

Results: Among the 52 suspected cases, 29 cases (56\%) were confirmed. In 13 (45\%) cases the diagnosis was determined through the specific series, which results in an $81 \%$ increase in the number of diagnoses.

STUDY LIMITATION: Small sample size.

Conclusions: Women were more commonly affected, with a mean time for the final diagnosis of 45 months, and the most common localization was the dorsum of the feet. There was an increase in diagnostic accuracy with the introduction of new haptens in the patch test of patients with suspected shoes dermatitis.
\end{abstract}

Keywords: Dermatitis, allergic contact; Foot; Patch tests; Shoes

\section{INTRODUCTION}

Shoes have been used by humans since the end of the Paleolithic to protect feet from environmental injuries. ${ }^{1}$ However, they have lately acquired new roles and are part of the most varied fashion styles. There are different types of shoes for different activities, such as sports, work and safety. ${ }^{2}$

Many materials are used in their making including leather, rubber, plastic, fabrics and glue, besides metal or plastic ornaments. There are still many chemical substances used in the production of the raw material for leather and rubber that can be released from the final product during its use by the consumer. Contact of any of these agents with the skin can induce the appearance of allergic contact dermatitis (ACD).

$\mathrm{ACD}$ is a late hypersensitivity reaction and, in the feet, can be caused by topical medications, powders, deodorants and shoes. The foot is a region particularly susceptible to ACD to shoes due to the concurrence of local events such as sweating, maceration and occlusion, all of which favor the penetration of allergens. ${ }^{2}$

Other skin conditions can mimic ACD on this site such as psoriasis, irritant dermatitis, tinea, dyshidrosis, lichen planus and juvenile plantar dermatosis. Therefore, a comprehensive investigation is man-

\footnotetext{
Received 19 June 2017.

Accepted 25 July 2017.

* Study conducted at the Dermatology Clinic, Santa Casa de São Paulo - São Paulo (SP), Brazil.

Financial support: None

Conflict of interest: None.

Dermatology Clinic, Santa Casa de São Paulo - São Paulo (SP), Brazil.
}

MAILING AdDREsS:

Rosana Lazzarini

E-mail: rosana.fototerapia@gmail.com

C2018 by Anais Brasileiros de Dermatologia 
datory in order to determine the best treatment for the patients. ${ }^{2}$

ACD etiologic agents are investigated through patch tests. The application of these tests involves the use of allergen series manufactured specifically for this purpose. The Brazilian standard series contains the allergens most commonly involved in reactions caused by shoes. However, there are complementary series, such as the shoe series, used to improve diagnostic accuracy in many other countries. Nonetheless, there are no studies in our country demonstrating the utility of these complementary series.

The primary objective of the present study was to measure the increase in efficacy in diagnostic accuracy of ACD to shoes with the use of a specific complementary series in contact tests.

Secondarily, we described the characteristics of the affected population such as gender, site of the lesions, time of evolution of the condition and most common allergens.

\section{METHOD}

We conducted a retrospective evaluation of patients with the diagnostic hypothesis of allergic contact dermatitis to shoes that were patch tested between November 2010 and April 2016.

The tests were performed with the Brazilian standard series, with 30 substances (FDA Allergenic, RJ, Brazil), complemented by additional 13 substances that are part of the shoe series (Chemothecnique, Malmo, Sweden) (Chart 1 and 2).

The tests were applied on the upper back of the patients, using FINN Chambers patches (Smart Practice, USA). The readings followed the criteria from the International Contact Dermatitis Research Group (ICDRG) of 1981.

Patients of any gender and age group were tested, and patients with the excited skin syndrome were excluded.
Sources for the research were patients files and a specific form where data from the patients that underwent patch tests in our unit were collected.

Data were catalogued in an Excel $^{\circledR}$ (Microsoft, USA) spreadsheet for subsequent analysis with the chi-square and Fisher's exact (two-tailed) tests of data from the study itself and for comparison with results from the literature. The significance level adopted was of 0.01 .

\section{CHART 2: Components of the shoe series}

\begin{tabular}{|c|c|c|}
\hline Substance & Concentration $(\%)$ & Vehicle \\
\hline IPPD $^{1}$ & 0.1 & Petroleum jelly \\
\hline Glutaraldehyde & 0.2 & Petroleum jelly \\
\hline Disperse Orange 3 & 1.0 & Petroleum jelly \\
\hline Acid Yellow 36 & 1.0 & Petroleum jelly \\
\hline $\begin{array}{l}\text { Hydroquinone } \\
\text { monobenzyl ether }\end{array}$ & 1.0 & Petroleum jelly \\
\hline 4, $\mathrm{PPD}^{2}$ & 1.0 & Petroleum jelly \\
\hline $\mathrm{DPTU}^{3}$ & 1.0 & Petroleum jelly \\
\hline Diethyl thiourea & 1.0 & Petroleum jelly \\
\hline 1.3-Diphenylguanidine & 1.0 & Petroleum jelly \\
\hline n,n-Dibutyl thiourea & 1.0 & Petroleum jelly \\
\hline Dodecyl mercaptan & 0.1 & Petroleum jelly \\
\hline $\mathrm{OIT}^{4}$ & 0.1 & Petroleum jelly \\
\hline 4.4-Dithiomorpholine & 1.0 & Petroleum jelly \\
\hline
\end{tabular}

(1) n,isopropyl-n-phenyl-4-phenylenediamine; (2) 4-paraphenylenediamine;

(3) n,n-diphenylthiourea; (4) 2-n-octyl-isothiazolinone-3-one

\begin{tabular}{|c|c|c|c|c|c|}
\hline Substance & Concentration & Vehicle & Substance & Concentration & Vehicle \\
\hline Anthraquinone & $2.0 \%$ & Petroleum jelly & Neomycin & $20.0 \%$ & Petroleum jelly \\
\hline Balsam of Peru & $25.0 \%$ & Petroleum jelly & Nitrofurazone & $1.0 \%$ & Petroleum jelly \\
\hline Benzocaine & $5.0 \%$ & Petroleum jelly & Parabens2 & $12.0 \%$ & Petroleum jelly \\
\hline Potassium dichromate & $0.5 \%$ & Petroleum jelly & Paraphenylenediamine & $1.0 \%$ & Petroleum jelly \\
\hline p-tert-Butylphenol & $3.0 \%$ & Petroleum jelly & Perfume-mix3 & $8.0 \%$ & Petroleum jelly \\
\hline Carba mix 1 & $3.0 \%$ & Petroleum jelly & PPD- mix 4 & $0.6 \%$ & Petroleum jelly \\
\hline Cobalt chloride & $1.0 \%$ & Petroleum jelly & Promethazine & $1.0 \%$ & Petroleum jelly \\
\hline Colophony & $20.0 \%$ & Petroleum jelly & Propylene glycol & $1.0 \%$ & Petroleum jelly \\
\hline Ethylenediamine & $1.0 \%$ & Petroleum jelly & Quaternium 15 & $2.0 \%$ & Petroleum jelly \\
\hline Formaldehyde & $2.0 \%$ & Water & Quinoline-mix5 & $5.0 \%$ & Petroleum jelly \\
\hline Hydroquinone & $1.0 \%$ & Petroleum jelly & Epoxy-resin & $1.0 \%$ & Petroleum jelly \\
\hline Triclosan & $1.0 \%$ & Petroleum jelly & Nickel sulfate & $5.0 \%$ & Petroleum jelly \\
\hline Kathon CG & $0.5 \%$ & Petroleum jelly & Turpentine & $10.0 \%$ & Petroleum jelly \\
\hline Lanoline & $20.0 \%$ & Petroleum jelly & Thimerosal & $0.1 \%$ & Petroleum jelly \\
\hline Mercaptobenzothiazole & $1.0 \%$ & Petroleum jelly & Thiuram-mix6 & $1.0 \%$ & Petroleum jelly \\
\hline
\end{tabular}

(1) Diphenylguanidine, zinc dibutyldithiocarbamate, zinc dimethylcarbamate; (2) Butyl, ethyl, propyl, methylparabens; (3) Amyl cinnamal, cinnamal, cinammyl alcohol, eugenol, oak moss absolute, geraniol, hydroxycitronellal, isoeugenol 1\% each; (4) N-phenyl-n-cyclohexyl-p-phenylenediamine, N-iso-N-phenyl-p-phenylenediamine, N-N-diphenyl-p-phenylenediamine, $0.2 \%$ each; (5) Clioquinol, clorquinaldol, $3 \%$ each 
The present study was approved by the Committee of Ethics in Research under the protocol number 66757416.3.0000.5479.

\section{RESULTS}

From November 2010 to April 2016, 554 patients with the diagnostic hypothesis of allergic contact dermatitis were patch tested in the Dermatology clinic. In this group, 52 (9.4\%) had the diagnostic hypothesis of $\mathrm{ACD}$ to shoes and underwent contact tests.

Among the 52 cases with suspected ACD to shoes, 29 (56\%) were confirmed. The confirmation of the diagnosis with the standard series was possible in 16 cases (55\%), while in 13 (45\%) the diagnosis required the use of the shoes series. The association of both series improved the diagnosis in $81 \%$, i.e., from 16 to 29 cases.

Of the 52 patients, 34 (65\%) were female; the mean age was 45 years and the median 50. Caucasian were 33 (63\%), brown, 10 (19\%), dark-skinned, 7 (13\%), and Asian, 2 (4\%). The time of evolution of the condition ranged between 30 days and 23 years, with the mean of 45 months and median of 24 .

The condition affected the dorsum of the feet and toes in 20 cases (69\%), the plantar region in 17 (58.6\%), the heel in 10 (34.5\%) and in 4 , the plantar arch $(13.8 \%)$, with some patients having more than 1 region affected. The dorsum of the feet and the plantar region were the only ones affected in 5 cases (17.2\%) each and the heel in 1 (3.4\%).

The number of positive reactions to shoe-related allergens in the Brazilian standard series were: $12(41.4 \%)$ to nickel sulfate, 6 (20.7\%) to cobalt chloride, 4 (13.8\%) to PPD mix, 4 (13.8\%) to potassium dichromate, $2(6.9 \%)$ to colophony, 1 (3.4\%) to p-ter-butylphenol, thiuram, carba mix, and formaldehyde. All patients had more than 1 positive test, with a mean of 1.7 substance per patient (Table 1 ).

Shoe series was positive for the following substances: 4.4-dithiomorpholine in 8 cases (27.6\%), 1.3-diphenylguanidine in 4 $(13.8 \%)$, glutaraldehyde in $3(10.3 \%)$, dodecyl mercaptan and 2-n-octyl-4-isothiazolinone (OIT) in 2 each (6.9\%) and 4-paraphenylenediamine in 1 case $(3.4 \%)$. Other substances such as IPPD, disperse orange 3, acid yellow 36, hydroquinone monobenzyl ether, n,n-diphenylthiourea, diethyl and dibutyl thiourea were negative in all cases (Table 1).

Shoe components responsible for ACD were: rubber in 16 cases $(55.2 \%)$, metal ornaments in $11(38 \%)$, leather in $9(31 \%)$, and adhesives in $4(13.8 \%)$, with some patients presenting sensitivity to more than one shoe component. In 10 cases (34.5\%) rubber was the only component involved in ACD, metal ornaments in 5 (17.2\%), leather in $4(13.8 \%)$ and adhesives in $2(6.9 \%)$. The 11 patients with sensitivity to the metallic shoe ornament had lesions on the dorsum of the foot or of the toes $(p<0.01)$.

Other substances unrelated to shoes but positive in the patch tests were: neomycin in 8 cases $(27.6 \%)$, perfume mix in 3 $(10.3 \%)$, parabens and promethazine in $2(6.9 \%)$ each, and balsam of Peru, propylene glycol, ethylenediamine, quinoline and Kathon CG in 1 case each $(3.4 \%)$.

\section{DISCUSSION}

Shoe ACD is challenging for the attending physician and particularly for the patient, since shoes are not usually seen as caus-

\begin{tabular}{lll}
\multicolumn{3}{c}{ TABLE 1: Distribution of the positive and relevant substances in } \\
29 patients with shoe ACD
\end{tabular}

$\left({ }^{*}\right)$ More than 1 positive test per patient; $(p)=$ standard series; $(c)=$ shoe series

es of feet eczema. Quite often, lesions that affect the plantar region are mistaken for other skin conditions. As such, the careful evaluation of the clinical aspects and distribution of lesions can help with the diagnosis. Patch test complements clinical diagnosis in establishing the etiology, particularly in long-standing cases.

In the present study, shoe ACD was the diagnostic hypothesis in 52 cases among 554 patients (9.4\%) and it was confirmed in 29 of them (5.2\%). The estimated prevalence for shoe ACD is between $3.3 \%$ to $11.7 \%$ among patients with $\mathrm{ACD}$, or $1.5 \%$ to $24.2 \%$ among patients that undergo contact tests. ${ }^{2,3}$ Therefore, the frequency observed in this study is consistent with the literature; the small variations seen could be related to the groups of patients studied, to the methodology used and to the series used for the contact tests. These series vary according to the centers where the study is conducted and there is no consensus regarding the agents to be tested. ${ }^{2}$

In our study, most patients were diagnosed with the use of the standard series alone (16/55\%). However, in 13 cases (45\%), the diagnosis was only possible through the use of a specific series of shoe allergens, which increased diagnostic accuracy in $81 \%$. This shows the need to broaden the amount of allergens used in contact tests in our country, allowing for a higher number of etiological diagnoses.

Women were the most affected $(65 \%)$ in the group studied. Despite the fact the condition affects both genders the results in the literature are conflicting. In some studies, men are most commonly affected, what is explained by the fact that this group tends to have closed shoes on for longer periods of time. On the other hand, in other studies women are more frequently affected seemingly by the fact that they use a larger variety of shoe types, exposing them to a higher number of haptens, and also because they care more about 
their health and seek medical assistance more frequently. ${ }^{2}$ In this study, we believe that both factors could have contributed to the higher frequency of women in the group.

The higher number of Caucasian patients (33/63\%) and mean age of 45 years reflects the population seen at the outpatient clinic.

The time between the onset of the problem and the diagnosis had a mean of 45 months, reflecting the diagnostic difficulty and the delay in performing contact tests. In some cases, the condition was present for longer than 10 years.

The most frequent location was the dorsum of the feet and toes. These data are in accordance with the literature, because these are the areas in closer contact with the shoes and where the stratum corneum in thinner. Areas with less contact, such as the plantar arch and toe web spaces, or those with a thicker stratum corneum as the heels are usually spared. ${ }^{4}$

Rubber was the shoe component responsible for the larger number of cases $(55.2 \%)$. It is present in insoles, soles and elastics. The diagnoses were confirmed through the positivity to carba mix, thiuram mix, PPD mix, 1.3-diphenylguanidine, paraphenylenediamine and 4.4-dithiomorpholine, with the three last present in the shoe series. In these cases, the dermatitis affected the plantar region and was related to the soles. One of the cases with lesions on the hands and forearms was considered occupational in a patient who was a shoemaker.

Ornaments used in shoes were responsible for 11 (38\%) ACD cases and all had lesions on the dorsum of the feet and toes. The prolonged contact with metal associated to sweating and friction are contributing factors. There are variations in the literature regarding the frequency of this allergen in shoes; however, in our country, nickel and cobalt allergy is common, what explains this high frequency. ${ }^{5}$

Another frequent component was leather, present in 9 cases (31\%), with the most common allergen being chromium, an agent used in the hardening process. This method uses trivalent chromium salts such as chromic acid, chromic sulfate and chromium trichloride that bind to the collagen, stabilizing the leather. However, the trivalent form can undergo oxidation during hardening, transforming it into hexavalent, a known allergen that does not adhere adequately to leather collagen. It remains in the free form and is capable of reaching the user's skin, triggering ACD. ${ }^{6}$ Other positive allergens related to hardening were glutaraldehyde (3/10.3\%), OIT
$(2 / 6.9 \%)$ and formaldehyde (1/3.4\%). These substances can be used in hardening after the application of chromium and also as agents to improve the quality of the color and help with washing the final product, considered infrequent allergens. ${ }^{7}$ OIT is part of the isothiazolinone group, whose sensitization frequencies have increased all over the world. It is used in the textile and shoe industry to prevent contamination of fabrics, leathers and skins, mainly by fungi. A study published in 2016 shows that concurrent reactions with other isothiazolinones, such as methylisothiazolinone (MI) can occur. This can be a consequence of previous sensitization to MI in cosmetics. This event was not observed in the two cases positive for OIT. ${ }^{2,8}$

Adhesives used in shoes were accountable for 4 cases $(13.8 \%)$, and the allergens involved were colophony and dodecyl mercaptan $(2 / 6.9 \%)$, and p-tert-Butylphenol formaldehyde resin $(1 / 3.4 \%)$. In none of the cases these substances were positive simultaneously. Colophony and p-tert-butylphenol formaldehyde resin are components of neoprene glues used in fabric lining and insoles. In a study published in 2004 on feet contact dermatitis there were no positive cases to resin, what could suggest the low frequency of this allergen in our country or even the lack of diagnosis. ${ }^{9}$ Dodecyl mercaptan is a polyurethane resin polymerization-inhibiting agent, considered an infrequent allergen, not studied in our country.

Allergic contact dermatitis to shoes is difficult to diagnose, leading patients to using many topical medications on the affected area, enabling sensitization to them. This explains positive contact tests to neomycin, perfume mix, parabens, promethazine, balsam of Peru, propylene glycol, ethylenediamine, quinoline and Kathon CG, agents used as the active substances, preservatives and fragrances in medications and cosmetics.

\section{CONCLUSIONS}

We were able to detect in this study positive and relevant reactions to many haptens not well studied in our country. Some problems were observed, such as the difficulty in establishing the relevance of a positive test, since there is no description. As a consequence, advices given to patients regarding the appropriate shoe in a particular situation are compromised.

This study confirmed an increased diagnostic accuracy with the association of the specific shoe series to the standard Brazilian series in cases suspicious shoe ACD. With a larger number of cases and increased number of centers studying this subject are key to improve knowledge on the theme. 


\section{REFERENCES}

1. Historiadetudo.com [Internet]. História de tudo. História do sapato. [acesso 15 jun 2017]. Disponível em: www.historiadetudo.com/sapato [acesso em 15/06/17]

2. Matthys E, Zahir A, Ehrlich A. Shoe Allergic Contact Dermatitis. Dermatitis. 2014;25:163-71.

3. Warshaw EM, Schram SE, Belsito DV, DeLeo VA, Fowler JF Jr, Maibach HI, et al. Shoe allergens: retrospective analysis of cross-sectional data from the North American Contact Dermatitis Group, 2001-2004. Dermatitis. 2007;18:191-202.

4. Goossens A and Taylor J. Shoes. In Johansen JD, Frosch PJ, Lepoittevin J-P, editors. Contact Dermatitis. 5. ed. Berlin: Springer - Verlag Berlin Heidelberg; 2011. p. 819-830.

5. Duarte I, Tanaka MG, Suzuki MN, Lazzarini R. Patch test standard series recommended by the Brazilian Contact Dermatitis Study Group during the 20062011 period. An Bras Dermatol, 2013;88:1015-8.
6. Moretto A. Hexavalent and trivalent chromium in leather: what should be done? Regul Toxicol Pharmacol. 2015;73:681-6.

7. Geier J, Lessmann H. Leather and Shoes. In Rustemeyer T, Elsner P, John SM, Maibach HI, editors. Kanerva's Occupational Dermatology. 2. ed. Berlin: SpringerVerlag Berlin Heidelberg. 2012. p. 643-651.

8. Aerts $\mathrm{O}$, Meert H, Romaen E, Leysen J, Matthieu L, Apers S, et al. Octylisothiazolinone, an additional cause of allergic dermatitis caused by leather: case series and potential implications for the study of cross-reactivity with methylisothiazolinone. Contact Dermatitis. 2016;75:276-284.

9. Lazzarini R, Duarte I, Marzagão C. Contact dermatitis of the feet: study of 53 cases. Dermatitis. 2004;15:125-30.

\section{AUTHORS' CONTRIBUTIONS}

Rosana Lazzarini

(iD) ORCID 0000-0002-4893-3593

Approval of the final version of the manuscript, Design and planning of the study, Preparation and writing of the manuscript, Intellectual participation in propaedeutic and/or therapeutic conduct of studied cases

Rodolfo Ferreira Mendonça

(iD) ORCID 0000-0003-3429-0897

Statistical analysis, Collecting, analysis and interpretation of data, Critical review of the manuscript

Mariana de Figueiredo Silva Hafner

(iD) ORCID 0000-0001-8322-3856

Collecting, analysis and interpretation of data, Effective participation in research orientation, Intellectual participation in propaedeutic and/or therapeutic conduct of studied cases, Critical review of the manuscript

How to cite this article: Lazzarini R, Mendonça RF, Hafner MFS. Allergic contact dermatitis to shoes: contribution of a specific series to the diagnosis. An Bras Dermatol. 2018;93(5):696-700. 